m41.002

\section{Tuning cooperative effects in azole based iron(II) spin crossover coordination polymers}

\section{Yann Garcia \\ Unité de Chimie des Matériaux Inorganiques et Organiques, Département de Chimie, Faculté des Sciences, Université catholique de Louvain, Place Louis Pasteur 1, 1348 Louvain-la-Neuve, Belgium. E-mail: garcia@chim.ucl.ac.be. \\ Keywords: spin crossover, coordination polymers, supramolecular chemistry}

The spin crossover (SCO) phenomenon probably belongs to one of the most active field of investigation in structural and molecular chemistry [1]. Most of the structural investigations have been carried out for coordination compounds incorporating $3 \mathrm{~d}^{5}, 3 \mathrm{~d}^{6}$ and $3 \mathrm{~d}^{7}$ transition metal ions in octahedral surrounding, while the first crystal structures of a $3 \mathrm{~d}^{4}$ system in the high-spin and low-spin states has recently been communicated [2]. This phenomenon implies a variation of the $\mathrm{ML}_{6}$ geometry as well as of the unit cell, which can be tracked by $\mathrm{X}$-ray diffraction. Although the origin of the SCO phenomenon is molecular, its cooperative manifestation depends on an efficient coupling between the SCO species in the crystal lattice through covalent and supramolecular interactions [3].

Iron(II) 1,2,4-triazole and tetrazole coordination polymers have attracted particular interest as their abrupt spin transition is generally associated with both hysteretic and thermochromic effects, thus providing a basis for their potential use in thermal display and memory devices [3]. We will present our recent advances in this field and demonstrate that the nature and mechanical character of the bridging ligand play a crucial role on the elastic transmission of molecular distortions associated to the thermally induced $\mathrm{SCO}$ of isolated $\mathrm{Fe}^{\mathrm{II}}$ ions. The importance of supramolecular interactions on the existence of the switching mechanism itself will be addressed too [4].

[1] P. Gütlich, H. A. Goodwin, Top Curr Chem 233 (2004) 1.

[2] P. Guionneau, M. Marchivie, Y. Garcia, J. A. K. Howard, D. Chasseau, Phys. Rev. B 72 (2005) 214408.

[3] Y. Garcia, V. Niel, M. C. MuÒoz, J. A. Real, Top Curr Chem 233 (2004) 229.

[4] Y. Garcia, G. Bravic, C. Gieck, D. Chasseau, W. Tremel, P. Gütlich, Inorg. Chem. 44 (2005) 9723.

\section{m41.003}

\section{Photocrystallography with neutrons - Light-induced structural changes in $\left[\mathrm{Na}_{2}\left[\mathrm{Fe}(\mathrm{CN})_{5} \mathrm{NO}\right] \cdot 2 \mathrm{D}_{2} \mathrm{O}\right.$}

Dominik Schaniel, ${ }^{\mathrm{a}^{*}}$ Theo Woike, ${ }^{\mathrm{a}}$ Jürg Schefer, ${ }^{\mathrm{b}}$ Vaclav Petricek, ${ }^{\mathrm{c}}$ Karl W. Krämerd, Hansueli Güdeld

${ }^{a}$ Institut für Mineralogie, Universität zu Köln, Zülpicherstr. 49 b, 50674 Köln, Germany, ${ }^{b}$ Laboratory for Neutron Scattering, 5232 Villigen PSI, Switzerland, ${ }^{c}$ Institute of Physics, Academy of Sciences, Na Slovance 2, 18221 Praha 8, Czech Republic, and ${ }^{d}$ Department of Chemistry \& Biochemistry, University of Bern, Freiestr. 3, 3000 Bern 9, Switzerland. E-mail: dominik.schaniel@uni-koeln.de

\section{Keywords: neutron diffraction, photochromism, isomers}

Photocrystallography deals with the determination of light-induced structural changes [1]. A prominent and interesting example are the metastable states SI and SII, which can be generated in $\mathrm{Na}_{2}\left[\mathrm{Fe}(\mathrm{CN})_{5} \mathrm{NO}\right] \cdot 2 \mathrm{H}_{2} \mathrm{O}(\mathrm{SNP})$ by irradiation with light in the blue-green spectral range. At low temperatures these metastable states have a long lifetime, which allows for their structural investigation by $\mathrm{x}$-ray or neutron diffraction. Early structural investigations $[2,3]$ of these metastable states discovered only small changes in bond lengths and angles of the Fe-NO group, which could not satisfactorily explain the long lifetime. In 1997 a major breakthrough in the understanding of the metastable states was achieved as the results of an X-ray study [4] could be interpreted as linkage isomers of the NO ligand: an isonitrosyl configuration in the state SI and a side-on NO configuration in the state SII. These results were supported by calculations based on Density Functional Theory [5], which showed that the linkage isomers corresponded to energetic minima in the potential landscape. On the other hand the subsequent reinvestigation of the neutron results could not confirm the linkage isomer structures [6]. We present here two recent neutron diffraction studies $[7,8]$ on the light-induced metastable states SI and SII, using a specially built photocrystallographic setup at the single crystal diffractometer TriCS at SINQ, PSI Villigen [9]. They unambiguously show that the two metastable states correspond to nitrosyl linkage isomers. The neutron diffraction evidence is especially important for the state SI, where the isonitrosyl structure is hard to detect, as the $\mathrm{N}$ and $\mathrm{O}$ atoms only interchange their position. Here the neutrons offer the advantage of a significant difference in scattering lengths between $\mathrm{N}(9.36 \mathrm{fm})$ and $\mathrm{O}(5.803 \mathrm{fm})$.

[1] P. Coppens, I. Novozhilova, A. Kovalevski, Chem. Rev. 102, 86 (2002).

[2] M. Rüdlinger, J. Schefer, G. Chevrier, N. Furer, H. U. Güdel, S. Haussühl, G. Heger, P. Schweiss, T. Vogt, T. Woike, H. Zöllner, $Z$. Phys. B 83, 125 (1991).

[3] M. R. Pressprich, M. A. White, Y. Vekhter, P. Coppens, J. Am. Chem. Soc. 116, 5233 (1994).

[4] M. D. Carducci, M. R. Pressprich, P. Coppens, J. Am. Chem. Soc. 119, 2669 (1997).

[5] B. Delley, J. Schefer, Th. Woike, J. Chem. Phys. 107, 10067 (1997).

[6] J. Schefer, Th. Woike, S. Haussühl, M. D. Fernandez Diaz, Z. Krist. 212, 29 (1997).

[7] D. Schaniel, Th. Woike, J. Schefer, V. Petricek, Phys. Rev. B 71, $174112(2005)$

[8] D. Schaniel, Th. Woike, J. Schefer, V. Petricek, K. W. Krämer, H. U. Güdel, Phys. Rev. B, submitted (2006).

[9] J. Schefer, D. Schaniel, Th. Woike, M. Imlau, Physica B 350, 87 (2004). 